\title{
Review Article
}

Neuropsychobiology

\section{Brain Structure and Subclinical Symptoms: A Dimensional Perspective of Psychopathology in the Depression and Anxiety Spectrum}

\author{
Bianca Besteher ${ }^{a} \quad$ Christian Gaser ${ }^{a, b}$ Igor Nenadićc \\ ${ }^{a}$ Department of Psychiatry and Psychotherapy, Jena University Hospital, Jena, Germany; ${ }^{b}$ Department of Neurology, \\ Jena University Hospital, Jena, Germany; ${ }^{C}$ Department of Psychiatry and Psychotherapy, Philipps University \\ Marburg/Marburg University Hospital - UKGM, Marburg, Germany
}

\section{Keywords}

Dimensional psychiatry - Voxel-based morphometry .

Cortical thickness - Gyrification - Default mode network

\begin{abstract}
Human psychopathology is the result of complex and subtle neurobiological alterations. Categorial DSM or ICD diagnoses do not allow a biologically founded and differentiated description of these diverse processes across a spectrum or continuum, emphasising the need for a scientific and clinical paradigm shift towards a dimensional psychiatric nosology. The subclinical part of the spectrum is, however, of special interest for early detection of mental disorders. We review the current evidence of brain structural correlates (grey matter volume, cortical thickness, and gyrification) in non-clinical (psychiatrically healthy) subjects with minor depressive and anxiety symptoms. We identified 16 studies in the depressive spectrum and 20 studies in the anxiety spectrum. These studies show effects associated with subclinical symptoms in the hippocampus, anterior cingulate cortex, and anterior insula similar to major depression and changes in amygdala similar to anxiety disorders. Precuneus and temporal areas as parts of the default mode network were affected specifically in the subclinical studies. We derive several methodical considerations crucial to investigations of
\end{abstract}

brain structural correlates of minor psycho(patho)logical symptoms in healthy participants. And we discuss neurobiological overlaps with findings in patients as well as distinct findings, e.g. in areas involved in the default mode network. These results might lead to more insight into the early pathogenesis of clinical significant depression or anxiety and need to be enhanced by multi-centre and longitudinal studies.

(c) 2019 S. Karger AG, Basel

Human psychopathology, emotions, cognitions, and behaviours are just as complex as the human brain itself and their underlying neurobiology.

Yet still, clinical psychiatry and research depend on categorical diagnoses defined in ICD-10 or DSM-5. These categories rarely capture each individual's symptom profile and are thus not able to distinguish between neurobiologically distinct disease entities $[1,2]$. For example, the "major depression" diagnostic category is composed of several different, sometimes even opposing symptoms [3]. On the other hand, minor symptoms in otherwise healthy persons cannot be categorised and therefore not be accounted for in healthy study participants, in at-risk subjects or in the psychiatric history of a patient, because the cut-off is set to separate clinical pathology from "sanity." One example is the "soft bipolar spectrum," which is

\section{KARGER}

(C) 2019 S. Karger AG, Basel

karger@karger.com

www.karger.com/nps
Dr. Bianca Besteher

Department of Psychiatry and Psychotherapy, Jena University Hospital Philosophenweg 3

DE-07743 Jena (Germany)

E-Mail bianca.besteher@med.uni-jena.de 
mostly disregarded in ICD-10, and DSM-5, but has contributed greatly to individual case history comprehension [4-6]. Of course, the categorical approach seems practical considering training, clinical and scientific application, epidemiologic enquiries, health insurance issues, and communication between professionals.

But there is a major downside for clinical practice, because if the current psychiatric nosology does not sufficiently capture the individual symptom constellation and pathogenesis, information is lost and treatment response may be suboptimal $[7,8]$, which impedes "precision psychiatry." In typical psychiatric case-control studies, cohorts are mostly chosen according to presence or absence of DSM-5 or ICD-10 diagnoses and therefore do not specifically consider the neurobiological substrate and aetiology of the particular psychiatric illness. This is also an obstacle for research on neurobiological markers in atrisk subjects with subclinical symptoms. As a consequence of this lack of neurobiologically driven research, pharmacological and other research on mental disorders has seen a recent decline due to the lack of identified biomarkers and specific therapeutic targets $[9,10]$, emphasising the need for a paradigm shift towards a fully dimensional scope of psychiatric disorders.

The idea of dimensional psychiatry is old though. One of the major dimensional models introduced to the scientific community was the endophenotype concept of schizophrenia by Gottesmann and Shields [11, 12], covering the genetic foundation, endophenotype and reaction surface with intra-individual shifting by age. But the idea only slowly translated into research or clinical practice. The current versions of ICD-11 and DSM- 5 have adopted some dimensional aspects but have refrained from making radical changes [13]. More ground-breaking efforts are the Hierarchical Taxonomy Of Psychopathology (HiTOP) for clinical practice [14] and the Research Domain Criteria (RDoC) by the National Institute of Mental Health [15] and the European "Roadmap for Mental Health Research" (ROAMER) [16] for scientific application.

There is considerable support for a dimensional approach with evidence for a neurobiological overlap of nominally distinct psychiatric disorders on several levels, starting with genes $[17,18]$ and spanning molecules [19], cells [20], brain structure [21, 22] and function [23, 24], as well as cognitive psychology [25]. And there is also evidence for alterations of brain structure and function associated with psychopathological symptoms in clinically healthy or at-risk patients not meeting the ICD or DSM cut-off [26]. Such findings open up new perspectives for

Brain Structure and Subclinical Symptoms understanding pathophysiology and early diagnosis of mental illnesses.

The aim of this review is to summarise the current evidence for this ongoing paradigm shift towards a neurobiologically founded, dimensional psychiatric nosology based on structural imaging findings (voxel-based morphometry [VBM], cortical thickness, and gyrification) in psychiatrically healthy subjects with minor depressive and anxiety symptoms. Studies covering this non-clinical spectrum are expected to expand our understanding of a dimensional continuum onto the neurobiological level.

Analysis of brain structure from MRI scans, especially using VBM, is a highly standardised and automated process applied in many studies across psychopathological dimensions [27]. These analyses are mostly analyses across the whole-brain and structural alterations and are considered to be relatively stable (although modifiable) over time [28]. In addition, multiple surface-based methods have emerged, including cortical thickness and gyrification, with the latter presumably being temporally stable from a very early age onwards $[29,30]$. We aim to: (a) emphasise the great value of a dimensional scope for investigation of basic neurobiological links to common psychopathological symptoms; (b) draw conclusions about the pathogenesis of psychopathological symptoms from the findings in both the depressive and anxiety spectrum; and (c) identify problems and perspectives for further investigation of the underlying neurobiology of psychopathological symptoms in healthy participants.

We searched PubMed for the literature using structural imaging findings of associations of grey matter volume (GMV), cortical thickness, and gyrification with subclinical psycho(patho)logical symptoms in healthy participants in the spectra of (1) depressive symptoms and (2) symptoms of anxiety. We did not apply a filter for the year of publication and used a couple of search terms in "all fields" to cover the three imaging modalities of cortical volume, cortical thickness and gyrification: "subclin* depr* AND cortical volume," "subclin* depr* AND cortical thickness," "subclin* depr* AND gyrification," "trait anx* AND cortical volume," "trait anx* AND cortical thickness," "trait anx* AND gyrification."

\section{Brain Structure and Subclinical Depressive Symptoms}

Sixteen original research papers have been published over the last decade applying different measures of GMV or cortical thickness and subclinical depressive symp- 
Table 1. Summary of the published reports of significant associations (corrected for multiple comparisons if not mentioned otherwise) between subclinical depressive symptoms and grey matter volume and cortical thickness

\begin{tabular}{lll}
\hline $\begin{array}{l}\text { First author } \\
\text { [Ref.], year }\end{array}$ & Participants, $n$ & Methods \\
\hline $\begin{array}{l}\text { Szymkowicz } \\
{[31], 2018}\end{array}$ & 80 & $\begin{array}{l}\text { FreeSurfer, GMV, ROIs: caudal } \\
\text { and rostral ACC, PCC, } \\
\text { hippocampus, and amygdala } \\
\text { BDI-II }\end{array}$ \\
& &
\end{tabular}

Results

Total BDI-II score inversely correlated with hippocampal

volume

Symptom subscales: more somatic symptoms inversely

correlated with posterior cingulate $(p=0.025)$ and

hippocampal volumes

Affective and cognitive subscales not associated with brain volumes in any regions of interest

\begin{tabular}{|c|c|c|}
\hline $\begin{array}{l}\text { Osler [32], } \\
2018\end{array}$ & $\begin{array}{l}\text { 192; male only } \\
51 \text { and } 59 \text { y old } \\
\text { (longitudinal } \\
\text { design) }\end{array}$ & $\begin{array}{l}\text { FreeSurfer, GMV, brain-wide } \\
\text { and ROIs: putamen, pallidum, } \\
\text { hippocampus and amygdala } \\
\text { volume and total cortical } \\
\text { thickness and ROIs: prefrontal } \\
\text { (dorsolateral, ventromedial) } \\
\text { thickness } \\
\text { In-house-software: hippocampal } \\
\text { and amygdala texture } \\
\text { MDI und BDI }\end{array}$ \\
\hline
\end{tabular}

O'Shea [33], 81; mean age 71 y $\quad$ FreeSurfer, GMV, ROIs:

2018 hippocampus, entorhinal cortex

BDI-II
Subclinical depressive symptoms at age 51 inversely correlated with total GMV and pallidum volume Inverse associations of subclinical depressive symptoms with total GMV and pallidum volume lost significance at age 59 Subclinical depressive symptoms at age 51 inversely associated with hippocampal volume at age 59 independent of later symptoms

Subclinical depressive symptoms at age 59 correlated positively with hippocampal and amygdala texture putative early markers of atrophy

Somatic symptoms negatively associated with total, right, and left hippocampal volumes

Affective symptoms negatively associated with total entorhinal cortex volumes

(uncorrected for multiple comparisons)

\begin{tabular}{lll}
\hline Szymkowicz & 73 ; mean age $71 \mathrm{y}$ & Freesurfer, cortical thickness \\
[46], 2017 & (CT) and surface area (SA), ROI: \\
& precuneus \\
& BDI-II
\end{tabular}

McLaren [44], 43; mean age 69 y FeeSurfer, GMV, whole brain 2017 CES-D

Somatic symptoms significantly negatively associated with age-related cortical thickness in precuneus

No associations with SA (uncorrected for multiple comparisons)

Positive associations between depressed mood, somatic symptoms, and lack of positive affect subscales with regional volumes in left inferior temporal lobe and (uncorrected) right paracentral and left superior temporal gyrus

Negative association of symptoms with the lingual gyrus GMV

\begin{tabular}{lll}
\hline Besteher [45], & $\begin{array}{l}\text { 177; mean age } \\
30 y\end{array}$ & VBM, GMV, whole brain \\
2017 & SCL-90-R depression subscale
\end{tabular}

Szymkowicz 43; mean age 69 y FreeSurfer, cortical thickness,

[42], $2016 \quad$ whole brain and ROIs: rostral ACC, OFC, middle frontal gyrus, isthmus cingulate

CES-D

McLaren [41], 41; mean age 70 y Freesurfer, GMV, ROI: cingulum 2016 CES-D
Depression subscale positively correlated with grey matter in the Rolandic operculum, superior temporal gyrus (left) and postcentral gyrus (bilateral)

Positive correlation of depressive symptoms and cortical thickness in the right isthmus cingulate in the ROI analysis and in the left precuneus in the vertex-wise analysis

\footnotetext{
Depressed mood subscale positively associated with GMV in the left posterior cingulate and negatively associated in the isthmus cingulate

Somatic symptoms subscale negatively associated with GMV in the posterior cingulate

Trend level-positive association between scores on the lack of positive affect subscale GMV in the ACC (uncorrected for multiple comparisons)
} 
Table 1 (continued)

\begin{tabular}{|c|c|c|c|}
\hline $\begin{array}{l}\text { First author } \\
\text { [Ref.], year }\end{array}$ & Participants, $n$ & Methods & Results \\
\hline $\begin{array}{l}\text { Carlson [43], } \\
2015\end{array}$ & $42 ;$ mean age $21 \mathrm{y}$ & $\begin{array}{l}\text { VBM, GMV, ROIs: dmPFC, } \\
\text { vmPFC, ACC } \\
\text { DASS }\end{array}$ & $\begin{array}{l}\text { dmPFC correlated with depressive symptoms } \\
\text { Moderated by gender: in males negative correlation } \\
\text { of GMV and depressive symptoms in dmPFC, no } \\
\text { relationship in females }\end{array}$ \\
\hline $\begin{array}{l}\text { Spalletta [34], } \\
2014\end{array}$ & $\begin{array}{l}102 ; \text { mean age } \\
43 \mathrm{y}\end{array}$ & $\begin{array}{l}\text { Volumetry, ROI: bilateral hippo- } \\
\text { campus } \\
\text { BDI-II }\end{array}$ & $\begin{array}{l}\text { Reduced bilateral hippocampal volume predicting } \\
\text { subclinical depressive phenomenology only in healthy } \\
\text { males (uncorrected for multiple comparisons) }\end{array}$ \\
\hline $\begin{array}{l}\text { Goveas [35], } \\
2011\end{array}$ & $\begin{array}{l}253 \text { (only female); } \\
\text { mean age } 71 \mathrm{y}\end{array}$ & $\begin{array}{l}\text { Volumetry } \\
\text { Group comparison with } n= \\
1,119 \text { participants with a score of } \\
0(\text { CES-D) } \\
\text { CES-D }\end{array}$ & $\begin{array}{l}\text { Depressive symptoms negatively associated with superior } \\
\text { and middle frontal gyral volumes } \\
\text { No differences in hippocampal and amygdala volumes } \\
\text { (uncorrected for multiple comparisons) }\end{array}$ \\
\hline $\begin{array}{l}\text { Dotson [36], } \\
2009\end{array}$ & $\begin{array}{l}110 \text {; longitudinal } \\
\text { mean age at } \\
\text { baseline } 69 \mathrm{y}\end{array}$ & $\begin{array}{l}\text { Volumetry, whole brain and } \\
\text { ROI: frontal and temporal } \\
\text { lobes, OFC, cingulate gyrus, } \\
\text { hippocampus } \\
\text { CES-D }\end{array}$ & $\begin{array}{l}\text { Mean depressive symptom scores over time negatively } \\
\text { associated with GMV in the left temporal lobe, cingulate } \\
\text { gyrus and OFC } \\
\text { Depressive symptoms not associated with hippocampus } \\
\text { volumes } \\
\text { (uncorrected for multiple comparisons) }\end{array}$ \\
\hline
\end{tabular}

ROI, region of interest; BDI, Beck's depression inventory; CES-D, Center for Epidemiologic Studies Depression Scale; OFC, orbitofrontal cortex; DASS, Depression, Anxiety, and Stress Scale; dmPFC, dorsomedial prefrontal cortex; vmPFC, ventromedial prefrontal cortex; GDS, Geriatric Depression Scale.

toms, sometimes focusing on subgroups (e.g., elderly subjects or females only). These studies are summarised in Table 1. The results are as heterogeneous as the chosen study protocols and raise several concerns that will be addressed later on. One very frequently discussed finding in the most recent studies is an association of hippocampal grey matter with subclinical depressive symptoms [3134], mostly a negative correlation. Older studies specifi- cally state no associations between subclinical depressive symptoms and hippocampal volume, though [35-37]. Another area of interest with reported structural alterations in some of these studies is the anterior cingulate cortex (ACC) [38], where an effect is shown mostly in women $[39,40]$, as well as less frequently in the posterior cingulate cortex and isthmus of the cingulate $[36,41,42]$. Less frequently and less consistently, other prefrontal ar- 
eas have been associated with subclinical depressive symptoms, mostly with negative correlations: the superior and middle frontal gyrus [35, 37, 38], dorsomedial prefrontal cortex (dmPFC) in men [43] and the orbitofrontal cortex (OFC) $[36,38]$. Superior and inferior temporal gyrus volume was positively correlated with subclinical depressive symptoms in 2 studies [44, 45] and negatively correlated in 2 other studies $[36,38]$.

Only 2 of the studies calculated cortical thickness and found inconsistent results of a negative correlation of symptoms with cortical thickness in precuneus [46] and positive correlation with cortical thickness in precuneus [42] in smaller groups ( $n=73$ and $n=43$, respectively) of elderly participants (mean age 71, 69 years, respectively). Associations of gyrification with subclinical depressive traits in non-clinical subjects have not yet been explored.

\section{Brain Structure and Subclinical Anxiety/Phobia Symptoms}

Twenty studies have reported brain structural alterations associated with subclinical anxiety symptoms, summarised in Table 2.

Correlations with amygdala volume have been investigated in multiple studies, some showing positive [4750], some negative [51-53] correlations of its (total) volume with subclinical anxiety. Other reported areas are the ACC $[53,54]$, insula and OFC $[47,52,55,56]$, hippocampus $[48,57,58]$, parahippocampal cortex (positive GMV correlation $[49,59]$ and negative GMV correlation [53]), and precuneus (negative GMV correlation [60], positive GMV correlation with state measures [45] and [55]). One study showed a negative correlation of gyrification of the precuneus with trait anxiety [61].

Sporadically, studies imply that areas like the thalamus or hypothalamus have negative and positive GMV correlations [62] or lingual gyrus and temporal cortex have positive GMV correlations [63] and positive cortical thickness associations [47], inferior frontal cortex have negative GMV correlations [64], or left postcentral gyrus have negative GMV correlations [65].

\section{Methodical Considerations}

Summarising and comparing these studies highlights several methodological challenges irrespective of the examined spectrum. At first it is crucial to consider age and gender of the chosen cohort, which seem to have an impact on measured correlations. It seems plausible to expect structural variations relevant to the pathogenesis of MDD or an anxiety disorder in adolescents or young adults, because the peak onset for both spectra is at an age between 30 and 40 years. Studies in geriatric cohorts often analysed the subclinical depressive spectrum (Table 1) and are more relevant for investigation of geriatric psychiatric hypotheses. Aging effects on the brain structure mediated by altered connectivity have to be taken into account though [66].

Some analyses in both spectra describe a structural effect of gender on areas associated with subclinical symptoms. Since there is plenty of evidence for genetically driven differential neurodevelopment in men and women, especially with regard to psychopathology [67], there should be more analyses addressing the effect of gender in larger samples. For example, healthy hippocampus function as well as functional decline in illnesses like Alzheimer's disease or major depression is considerably modulated by gender, which can be demonstrated clinically, functionally, and structurally, thus hinting at gender-specific neurogenesis [68].

Another important issue is the direction of correlations in these studies. There is limited basic research to mechanistically explain how higher or lower GMV in a certain area affects its function. Under pathological conditions including atrophy, lower GMV is commonly assumed to lead to decreased function, because it is mostly found in functionally impaired subjects, i.e. in patients or in the aging brain [69]. A positive association of subclinical symptoms with GMV as in some of the mentioned studies appears less intuitive. However, these findings merit particular attention. Higher GMV could be mediated by multiple structural or functional effects, including volume of neuropil, glial cells, or tissue water as well as differences in synaptic pruning [70-72], lack of inhibition, or even rapid changes in T1 scans, probably reflecting regional cerebral blood flow [73]. Some studies report worse task performance is associated with larger cortical volume $[74,75]$. It is unclear whether there is a linear decreasing GMV curve for a certain brain area across a putative spectrum (i.e., from low depressive healthy over high depressive healthy to an MDD patient). Indeed, several recent studies using a correlational approach between subclinical or personality measures and brain structure have identified positive correlations [76-81]. There are several possible explanations to this, including a non-linear or "inverted U-shape curve" relationship, that would imply a positive correlation in the non-clinical part of the spectrum, but negative correlations in the pathological part of the spectrum. Another largely unex- 
Table 2. Summary of the published reports of significant associations (corrected for multiple comparisons if not mentioned otherwise) between subclinical anxiety symptoms and grey matter volume (GMV) and cortical thickness

\begin{tabular}{|c|c|c|c|}
\hline $\begin{array}{l}\text { First author } \\
\text { [Ref.], year }\end{array}$ & Participants, $n$ & Methods & Results \\
\hline Wu [59], 2018 & $\begin{array}{l}140 \text {; age range } \\
17-21 \mathrm{y}\end{array}$ & $\begin{array}{l}\text { VBM, GMV, whole brain } \\
\text { STAI }\end{array}$ & $\begin{array}{l}\text { Trait anxiety positively correlated with GMV in the } \\
\text { parahippocampal gyrus }\end{array}$ \\
\hline $\begin{array}{l}\text { Modi [62], } \\
2018\end{array}$ & 76 ; mean age $23 \mathrm{y}$ & $\begin{array}{l}\text { VBM, GMV, ROIs: } \\
\text { hippocampus, amygdala, ACC, } \\
\text { thalamus, hypothalamus, } \\
\text { DLPFC, RLPFC, VLPFC } \\
\text { STAI }\end{array}$ & $\begin{array}{l}\text { Trait anxiety negatively correlated with GMV of } \\
\text { hypothalamus bilaterally and positively correlated with } \\
\text { GMV of left thalamus } \\
\text { (uncorrected for multiple comparisons) }\end{array}$ \\
\hline $\begin{array}{l}\text { Besteher [63], } \\
2018\end{array}$ & 409; mean age $30 \mathrm{y}$ & $\begin{array}{l}\text { VBM, GMV, whole brain } \\
\text { SCL-90-R phobia subscale }\end{array}$ & $\begin{array}{l}\text { Positive correlations of GMV with phobia symptoms in } \\
\text { the right lingual gyrus, bilateral calcarine sulcus, left } \\
\text { superior, middle, and inferior temporal gyri }\end{array}$ \\
\hline $\mathrm{Hu}[51], 2017$ & 46 ; mean age $24 \mathrm{y}$ & $\begin{array}{l}\text { Manual tracing, amygdala } \\
\text { volume only } \\
\text { STAI }\end{array}$ & $\begin{array}{l}\text { Trait anxiety negatively correlated with left amygdala } \\
\text { volume }\end{array}$ \\
\hline $\begin{array}{l}\text { Besteher [45], } \\
2017\end{array}$ & 177 ; mean age $30 \mathrm{y}$ & $\begin{array}{l}\text { VBM, GMV, whole brain } \\
\text { SCL-90-R anxiety subscale }\end{array}$ & $\begin{array}{l}\text { Subclinical symptoms of anxiety positively correlated } \\
\text { with middle temporal gyrus, Rolandic operculum, } \\
\text { middle cingulate gyrus and precuneus bilaterally }\end{array}$ \\
\hline $\begin{array}{l}\text { Miskovich } \\
{[61], 2016}\end{array}$ & $113 ;$ mean age $22 \mathrm{y}$ & $\begin{array}{l}\text { FreeSurfer LGI, gyrification, } \\
\text { whole brain } \\
\text { STAI }\end{array}$ & $\begin{array}{l}\text { Negative correlation between trait anxiety and } \\
\text { gyrification in the left superior parietal cortex, } \\
\text { specifically the precuneus }\end{array}$ \\
\hline $\begin{array}{l}\text { Donzuso [55], } \\
2014\end{array}$ & $121 ;$ mean age $39 \mathrm{y}$ & $\begin{array}{l}\text { FreeSurfer: volumetry of } \\
\text { hippocampus and amygdala and } \\
\text { cortical thickness, ROIs: medial } \\
\text { and lateral OFC, rostral and } \\
\text { caudal-anterior ACC, amygdala, } \\
\text { hippocampus } \\
\text { VBM, same ROIs and whole } \\
\text { brain } \\
\text { STAI, HARS }\end{array}$ & $\begin{array}{l}\text { HARS positively correlated with cortical thickness in } \\
\text { ACC, no correlation found for STAI } \\
\text { HARS positively correlated with GMV in ACC and } \\
\text { OFC, no correlation found for STAI } \\
\text { STAI-state positively correlated with GMV in medial } \\
\text { motor and premotor areas } \\
\text { STAI-trait scores positively correlated with GMV in } \\
\text { precuneus }\end{array}$ \\
\hline
\end{tabular}


Table 2 (continued)

\begin{tabular}{|c|c|c|c|}
\hline $\begin{array}{l}\text { First author } \\
\text { [Ref.], year }\end{array}$ & Participants, $n$ & Methods & Results \\
\hline $\begin{array}{l}\text { Fuentes [60], } \\
2012\end{array}$ & 114 ; mean age $27 \mathrm{y}$ & $\begin{array}{l}\text { VBM, GMV, whole brain and } \\
\text { ROIs: hippocampus, amygdala } \\
\text { BIS }\end{array}$ & $\begin{array}{l}\text { BIS scores negatively correlated with GMV in } \\
\text { precuneus and OFC }\end{array}$ \\
\hline Baur [48], 2012 & 32 ; mean age $25 \mathrm{y}$ & $\begin{array}{l}\text { FreeSurfer, GMV, ROIs: uncinate } \\
\text { fasciculus, amygdala, } \\
\text { hippocampus } \\
\text { (uncorrected for multiple } \\
\text { comparisons only) } \\
\text { STAI }\end{array}$ & $\begin{array}{l}\text { Trait anxiety negatively correlated with UF volume and } \\
\text { positively correlated with amygdala and hippocampal } \\
\text { volume } \\
\text { (uncorrected for multiple comparisons) }\end{array}$ \\
\hline $\begin{array}{l}\text { Kuhn [56], } \\
2011\end{array}$ & 34 ; mean age $31 \mathrm{y}$ & $\begin{array}{l}\text { FreeSurfer, cortical thickness, } \\
\text { whole brain } \\
\text { STAI }\end{array}$ & $\begin{array}{l}\text { Trait anxiety negatively correlated with cortical } \\
\text { thickness right mOFC and positively correlated with the } \\
\text { bilateral volume of NAcc }\end{array}$ \\
\hline $\begin{array}{l}\text { Spampinato } \\
{[53], 2009}\end{array}$ & 30 ; mean age $28 \mathrm{y}$ & $\begin{array}{l}\text { VBM, GMV, whole brain } \\
\text { STAI }\end{array}$ & $\begin{array}{l}\text { Anxiety ratings inversely correlated with GMV in } \\
\text { DLPFC, rostral ACC, posterior cortex, posterior and } \\
\text { retrosplenial cingulate cortex, left parahippocampal } \\
\text { gyrus, left amygdala } \\
\text { Positive correlations in ventrolateral PFC bilaterally } \\
\text { (all results uncorrected for multiple comparisons) }\end{array}$ \\
\hline $\begin{array}{l}\text { Yamasue [57], } \\
2008\end{array}$ & $\begin{array}{l}183 \text {; mean age } 29 \text { y } \\
\text { (male participants) } \\
\text { and } 28 \text { y (female } \\
\text { participants) }\end{array}$ & $\begin{array}{l}\text { VBM, GMV, whole brain and } \\
\text { ROIs: hippocampus, amygdala, } \\
\text { prefrontal cortex } \\
\text { HA subscale of the TCI }\end{array}$ & $\begin{array}{l}\text { HA inversely associated with GMV in the right } \\
\text { hippocampus } \\
\text { Female-specific inverse correlation of HA with GMV in } \\
\text { the left anterior PFC }\end{array}$ \\
\hline $\begin{array}{l}\text { Iidaka }[50] \\
2006\end{array}$ & 56 ; mean age $22 \mathrm{y}$ & $\begin{array}{l}\text { VBM, GMV, whole brain } \\
\text { HA of the TCI }\end{array}$ & $\begin{array}{l}\text { HA score positively correlated with the volume of the } \\
\text { left amygdala (significant only in female participants) } \\
\text { (uncorrected for multiple comparisons) }\end{array}$ \\
\hline $\begin{array}{l}\text { Barros- } \\
\text { Loscertales [49], } \\
2006\end{array}$ & 63 ; mean age $22 \mathrm{y}$ & $\begin{array}{l}\text { VBM, GMV, whole brain } \\
\text { SP subscale of SPSRQ }\end{array}$ & $\begin{array}{l}\text { SP scores positively correlated with GMV in the right } \\
\text { parahippocampus, amygdala, and hippocampus and in } \\
\text { the left anterior parahippocampus }\end{array}$ \\
\hline Pujol [54], 2002 & 100 ; mean age $26 y$ & $\begin{array}{l}\text { Volumetry and cortical surface } \\
\text { measure, ROI: ACC, } \\
\text { hippocampus, precuneus } \\
\text { HA subscale of the TCI }\end{array}$ & $\begin{array}{l}\text { Positive correlation of HA with cortical surface of the } \\
\text { right anterior cingulate gyrus } \\
\text { (uncorrected for multiple comparisons) }\end{array}$ \\
\hline
\end{tabular}

VBM, voxel-based morphometry; STAI, Spielberger's State-Trait Anxiety Inventory; ROI, region of interest; ACC, anterior cingulate cortex; RLPFC, rostrolateral prefrontal cortex; VLPFC, ventrolateral prefrontal cortex; SAS, Self-Rating Anxiety Scale; HARS, Hamilton Scale for Anxiety; BIS/BAS, Behavioral Inhibition System/ Behavioral Approach System; BAI, Beck Anxiety Inventory; TCI, Temperament and Character Inventory; HA, harm avoidance; SPSRQ, Sensitivity to Reward and Punishment Questionnaire; SP, sensitivity to punishment; UF, uncinate fasciculus; NAcc, nucleus accumbens. 
plored explanation might be related to resilience or compensation: relatively larger grey matter in non-clinical subjects might thus be an indicator of resilience to transition into a full clinical phenotype. This aspect highlights both a current problem in interpretation as well as a significant future potential of these studies in the non-clinical spectrum.

Moreover, the choice of the anatomical measure is crucial for the analysis of subclinical symptoms in healthy adults. Most of the studies performed morphometry of volume images using VBM, conventional volumetry or region-of-interest (ROI) atlas-based morphometry with FreeSurfer software (14 studies in the depressive spectrum, 18 in the anxiety spectrum). Only 2 studies investigated cortical thickness based on cortical surface estimations, using a vertex-wise measure of the distance between the cortical surface and the border between grey and white matter. Cortical volume on the other hand amalgamates aspects of cortical thickness, cortical surface, and folding. Grey matter changes can affect both measures in different ways, and it is recommended to use both techniques [82]. Yet, the interpretation of divergent results is not trivial, because the underlying neuroanatomical factors are incompletely understood. For example, a study in older adults indicated that cortical thickness was independent of the cortical neuron count, emphasising the role of glial components of the cortex [83]. Cortical thickness and surface area measurements were found to be genetically and phenotypically independent. While both thickness and area influenced volume measurements of cortical grey matter, volume was more closely related to surface area than cortical thickness [84].

One study in the subclinical anxiety spectrum measured the association of symptoms with gyrification [61]. This is an interesting structural feature for analysis, because cortical gyrification is assumed to take place prenatally and in the first months or years postnatally, remaining stable in adult life $[29,30]$. However, more recent studies show age-related neurodevelopmental changes in gyrification depending on the method used for analysis [85-87], possibly mediated by changes in cortical connectivity throughout the lifespan [88-90]. Thus, to understand the connection between changes of gyrification and a liability for anxiety or depression, longitudinal studies in adolescents or young adults in relation to their age are needed. Innovative measures like cortical complexity or sulcal depth [91] extend the spectrum of analysis for gyrification and should be assessed in future studies.

Most of the cited studies used a multiple regression model to correlate subclinical symptoms with a structur- al feature accounting for several confounding factors, which has been a common statistical approach for a long time [92]. Another technique in some of the studies was to artificially divide the healthy cohort into two groups without or with very light symptoms and with more severe symptoms (but still subclinical). Creating a casecontrol setting like this seems reasonable when there is a meaningful difference of symptom severity within the cohort but might decrease statistical power due to dividing and matching of the sample.

Another major issue is the choice of self-report instruments. For the depressive spectrum, studies mostly used the BDI-II, which typically captures symptoms during the preceding 2 weeks, while CES-D, DASS, GDS, and SCL$90-\mathrm{R}$ focus on 1 week prior to assessment. One might argue that a liability for or predisposition towards depressive mood as a trait also increases the probability for higher depressive state scores like these. But correlating state measures with brain structure might show volatile associations mediated by brain plasticity during stressful life events or even more transient changes like regional blood flow or regional blood volume. Trait measures appear more suitable to investigate predisposition towards certain symptoms.

In contrast, anxiety was mostly measured with the STAI as a trait anxiety measure, less frequently with other trait measures like the BIS, SPSRQ, and TCI or state measures like SCL-90-R and SAS accounting for symptoms of the preceding week.

The validity of the chosen questionnaire is of similar importance. The RDoC initiative (https://www.nimh. nih.gov/research-priorities/rdoc/index.shtml) makes recommendations about self-report measures reporting the neurobiologically distinct domain of negative valence containing reaction to loss and potential threat, which are the core concepts of the depressive/anxiety spectra. However, a current review argues that none of these suggested measures are specific to either loss or sustained threat [93], which necessitates a clear rationale for each included self-report instrument in a study, since there is little guidance from RDoC so far.

\section{Considerations in a Mechanistic Context}

An important step in interpreting the findings from the subclinical spectrum is to place them in the context of dimensional continuum models, i.e. including phenotype expression across the full spectrum. Discussing the neurobiological plausibility of these subclinical findings is 
potentially conflicting, because our models of depression and anxiety are derived from findings in case-control studies, which eliminate associations with subclinical symptoms in the healthy control group by design. Still, there are some similarities in the frequently emerging brain areas in patients and healthy participants, which will be discussed (separately for each spectrum).

\section{Depressive Spectrum: Subclinical to Clinical}

Major depression affects the structure, connectivity, and biochemistry of several, especially frontal brain areas implicated in cognitive control, emotion regulation, and memory processing [94]. Several studies have robustly shown evidence of grey matter reduction in the ACC [9597]. The ACC is involved in multiple cognitive and affective functions, such as decision-making [98], empathy [99], conflict-monitoring [100], working memory, attention, and information-processing [101]. In only 5 of the above-cited studies in subclinical cohorts, did the ACC show positive or negative correlations with subclinical depressive symptoms, with the largest study ( $n=810$ participants) demonstrating a negative correlation of GMV in bilateral ACC with symptoms only in females [39]. This might point towards a gender-specific development of non-clinical depressive symptoms or even insignificant structural change and involvement of ACC in subclinical or transient depressive symptoms.

Further structural abnormalities in depressive patients occur in the insula, pallidum, thalamus, and hippocampus [102-104]. The anterior insula is connected to the inferior frontal cortex and ACC and is involved in social-emotional and cognitive networks $[105,106]$. The thalamus also has multiple cortical connections and is linked to negative emotion-generating limbic structures, e.g. the amygdala [104]. These connections could underlie deficits in the top-down regulation of negative affects in MDD. The hippocampus is not only involved in memory processing $[107,108]$ but shows reduced volume in patients probably due to stress-related or/and repeated neurotoxic processes associated with cumulative exposure to stress and depressive symptoms $[109,110]$. Of these areas, the hippocampus is also the most investigated structure with negative volume correlations with subclinical depressive symptoms, which is comprehensible considering the short temporal perspective of the applied self-report measures and the suggested stress dependence of hippocampal volume. However, some other studies explicitly state no associations with hippocampal volume, similarly to the observations regarding the amygdala.
Associations of subclinical symptoms of several prefrontal areas (dmPFC, OFC, superior and middle frontal gyri) and the pallidum are reported similarly to the findings in MDD patients. Divergent to the observations in clinical populations, structural associations in the thalamus and insula are not reported and therefore probably not relevant in subclinical cohorts.

Our review also identified areas associated with subclinical symptoms (but not in the MDD literature) like the precuneus and superior temporal cortex GMV; these could play a singular role in early development of depressive symptoms. One might speculate a relation between these areas and the default mode network (DMN), which has been identified in functional MRI studies and is also associated with the posterior cingulate cortex and medial PFC $[111,112]$. The DMN is thought to mediate the psychological process of introspection and mental movement away from externally concentrated thoughts [113]. A majority of studies have demonstrated that the DMN is hyperactive in MDD, possibly leading to rumination as an important clinical feature of depressive patients [114, 115]. This observation is an interesting intersection with subclinical symptoms and might point out an early origin of depressive thoughts, probably even before emotion regulation is involved. However, since the structural substrate of the DMN as a functional construct is inconsistent in different studies, this idea needs further investigation.

There is also a study in untreated, first-episode, midlife MDD patients showing increased cortical thickness in the right medial orbitofrontal gyrus, pars opercularis, rostral middle frontal gyrus, and supramarginal gyrus. Increased thickness of rostral middle frontal gyrus was negatively correlated with depression severity on the Hamilton Depression Rating Scale (HDRS) [116], indicating that increased thickness might be present in milder cases or that it might represent a compensation for inflammatory factors or other aspects of the pathophysiology of MD. This could explain the positive correlations observed in the subclinical context.

\section{Anxiety Spectrum: Subclinical to Clinical}

Anxiety-related behaviours and thoughts in patients and healthy persons are suggested to correspond to morphological differences and functional alterations in a leftlateralised circuit with higher GMV in the amygdala and anterior parahippocampal gyrus (PHG) and lower GMV in the OFC extending into the perigenual ACC $[26,117]$.

The amygdala as the key structure of this circuit mediates fear experience and conditioning, as well as saliency 
detection [118-120] and emotional memory [121] via its connections with the memory structures in the medial temporal lobe. This includes the hippocampus and anterior PHG, which encodes emotional stimuli [122] and places them in a context [123]. PHG and the ventrolateral PFC (vlPFC) are modulated by amygdala input during emotionally engaged learning contexts [124]. The connection of OFC and ACC with the amygdala has been implicated in fear conditioning and suppression [125127]. Efficient emotion regulation depends on the balance between the PFC and amygdala activity; greater PFC activation reduces amygdala activation [128]; and deficits in emotion regulation reverse this hierarchy [129]. These functional observations are supported by structural findings of increased GMV in the left amygdala and anterior PHG and reduced GMV in OFC and ACC as well as altered WM microstructure in the uncinate fasciculus, cingulum, and other cortico-cortical tracts associated with poor emotion regulation and fear extinction [26]. Structural findings in amygdala, PHG, ACC, OFC, and other prefrontal areas in the majority of studies in this current review support this hypothesis indicating it to be a relevant mechanism in subclinical trait anxiety as well. But the direction of associations is not always as expected from defective fear extinction.

Apart from this mechanism, the studies in subclinical anxiety report alterations in sensory cortices like the somatosensory cortex, the auditory cortex and the visual cortex implicating changes in the processing of external stimuli. This corresponds with fMRI findings of reduced functional connectivity in these perceptual systems associated with high trait anxiety [130]. These findings are mostly not replicated in the studies of brain structure and trait anxiety and therefore seem to lack a structural correlate in most cases.

Again, precuneus and temporal areas are associated with subclinical anxiety symptoms similar to the observations in the depressive spectrum, hinting at possible neural overlaps with the DMN, although the structural overlap appears to be highly inconsistent. There are several functional and EEG studies stating a failure to synchronise DMN in healthy participants with high trait anxiety during resting state, probably reflecting a top-down cognitive control deficit [131]. A recent large meta-analysis showed a hypo-connectivity of the affective network with executive control network and the DMN and a decoupling of both networks in patients with anxiety disorders [132], which makes the structural finding in the subclinical cohorts relevant for the early development of a clinical anxiety disorder.

Brain Structure and Subclinical Symptoms

\section{Conclusion}

Summing up the neuro-mechanistic discussion, there is a lot of overlap between altered cortical structure associated with subclinical depressive or anxiety symptoms and findings in patients. The structural variation in the precuneus and temporal areas in subclinical symptoms in both spectra suggest functional and structural alterations of the DMN to be relevant in the subclinical symptom range. The significance of all these findings for the development of a clinical relevant mental illness has yet to be shown in longitudinal studies though. Regarding the methodical considerations, especially the types of structural and self-report measurement have to be chosen carefully and ideally consistent with a neurobiologically driven, dimensional scope of psychiatric nosology.

Taken together, these findings and progress in related future studies might pave the way for a fully dimensional understanding of depression and anxiety irrespectively of the changing categorical definitions of disorders. These efforts are in synch, but not dependent, on approaches like RDoC. Yet, they provide substantially larger opportunities for early intervention, adaptation of treatment programs, and thus moves towards individualised medicine or "precision psychiatry," which takes into account also those subclinical phenotypes that so far have received insufficient attention in clinical studies.

\section{Statement of Ethics}

The authors have no ethical conflicts to disclose.

\section{Disclosure Statement}

The authors have no conflicts of interest to declare.

\section{Funding Sources}

None of the authors received funding to create this paper.

\section{Author Contributions}

All authors planned the review. B.B. created the first draft of the manuscript, C.G. and I.N. contributed to the finalisation of the manuscript. 


\section{References}

1 Jablensky A. Psychiatric classifications: validity and utility. World Psychiatry. 2016 Feb; 15(1):26-31.

2 Kendell R, Jablensky A. Distinguishing between the validity and utility of psychiatric diagnoses. Am J Psychiatry. 2003 Jan;160(1): 4-12.

3 Goldberg D. The heterogeneity of "major depression”. World Psychiatry. 2011 Oct; 10(3): 226-8.

4 Akiskal HS, Pinto O. The evolving bipolar spectrum. Prototypes I, II, III, and IV [vii.]. Psychiatr Clin North Am. 1999 Sep;22(3): $517-34$.

5 Angst J, Gamma A, Benazzi F, Ajdacic V, Eich D, Rössler W. Toward a re-definition of subthreshold bipolarity: epidemiology and proposed criteria for bipolar-II, minor bipolar disorders and hypomania. J Affect Disord. 2003 Jan;73(1-2):133-46.

6 Craddock N, Jones I, Kirov G, Jones L. The Bipolar Affective Disorder Dimension Scale (BADDS) - a dimensional scale for rating lifetime psychopathology in bipolar spectrum disorders. BMC Psychiatry. 2004 Jul;4(1):19.

7 Baca-Garcia E, Perez-Rodriguez MM, Basurte-Villamor I, Fernandez del Moral AL, Jimenez-Arriero MA, Gonzalez de Rivera JL, et al. Diagnostic stability of psychiatric disorders in clinical practice. Br J Psychiatry. 2007 Mar;190(3):210-6.

8 Trivedi MH, Rush AJ, Wisniewski SR, Nierenberg AA, Warden D, Ritz L, et al.; STAR*D Study Team. Evaluation of outcomes with citalopram for depression using measurement-based care in STAR*D: implications for clinical practice. Am J Psychiatry. 2006 Jan; 163(1):28-40.

9 Naughton M, Clarke G, O'Leary OF, Cryan JF, Dinan TG. A review of ketamine in affective disorders: current evidence of clinical efficacy, limitations of use and pre-clinical evidence on proposed mechanisms of action. J Affect Disord. 2014 Mar;156:24-35.

10 Miller G. Is pharma running out of brainy ideas? Science. 2010 Jul;329(5991):502-4.

11 Gottesman II, Shields J. Genetic theorizing and schizophrenia. Br J Psychiatry. 1973 Jan; 122(566):15-30.

12 Gottesman II, Shields J. A polygenic theory of schizophrenia. Proc Natl Acad Sci USA. 1967 Jul;58(1):199-205.

13 Zachar P, First MB. Transitioning to a dimensional model of personality disorder in DSM 5.1 and beyond. Curr Opin Psychiatry. 2015 Jan;28(1):66-72.

14 Kotov R, Krueger RF, Watson D, Achenbach TM, Althoff RR, Bagby RM, et al. The Hierarchical Taxonomy of Psychopathology (HiTOP): A dimensional alternative to traditional nosologies. J Abnorm Psychol. 2017 May; 126(4):454-77.
15 Insel T, Cuthbert B, Garvey M, Heinssen R, Pine DS, Quinn K, et al. Research domain criteria (RDoC): toward a new classification framework for research on mental disorders. Am J Psychiatry. 2010 Jul;167(7):748-51.

16 Haro JM, Ayuso-Mateos JL, Bitter I, Demotes-Mainard J, Leboyer M, Lewis SW, et al. ROAMER: roadmap for mental health research in Europe. Int J Methods Psychiatr Res. 2014 Jan;23(S1 Suppl 1):1-14.

17 Smoller JW, et al.; Cross-Disorder Group of the Psychiatric Genomics Consortium. Identification of risk loci with shared effects on five major psychiatric disorders: a genomewide analysis. Lancet. 2013 Apr;381(9875): 1371-9.

18 Craddock N, Owen MJ. The Kraepelinian dichotomy - going, going... but still not gone. $\mathrm{Br}$ J Psychiatry. 2010 Feb;196(2):92-5.

19 Krishnan V, Nestler EJ. Linking molecules to mood: new insight into the biology of depression. Am J Psychiatry. 2010 Nov; 167(11): 1305-20.

20 Swardfager W, Rosenblat JD, Benlamri M, McIntyre RS. Mapping inflammation onto mood: inflammatory mediators of anhedonia. Neurosci Biobehav Rev. 2016 May;64:148-66.

21 Hulshoff Pol HE, van Baal GC, Schnack HG Brans RG, van der Schot AC, Brouwer RM, et al. Overlapping and segregating structural brain abnormalities in twins with schizophrenia or bipolar disorder. Arch Gen Psychiatry. 2012 Apr;69(4):349-59.

22 Goodkind M, Eickhoff SB, Oathes DJ, Jiang Y, Chang A, Jones-Hagata LB, et al. Identification of a common neurobiological substrate for mental illness. JAMA Psychiatry. 2015 Apr;72(4):305-15.

23 Drysdale AT, Grosenick L, Downar J, Dunlop K, Mansouri F, Meng Y, et al. Resting-state connectivity biomarkers define neurophysiological subtypes of depression. Nat Med. 2017 Jan;23(1):28-38.

24 Hägele C, Schlagenhauf F, Rapp M, Sterzer P, Beck A, Bermpohl F, et al. Dimensional psychiatry: reward dysfunction and depressive mood across psychiatric disorders. Psychopharmacology (Berl). 2015 Jan;232(2):33141.

25 Catalan A, Gonzalez de Artaza M, Bustamante S, Orgaz P, Osa L, Angosto V, et al. Differences in Facial Emotion Recognition between First Episode Psychosis, Borderline Personality Disorder and Healthy Controls. PLoS One. 2016 Jul;11(7):e0160056.

26 Mincic AM. Neuroanatomical correlates of negative emotionality-related traits: A systematic review and meta-analysis. Neuropsychologia. 2015 Oct;77:97-118.

27 Mitelman SA. Transdiagnostic neuroimaging in psychiatry: A review. Psychiatry Res. 2019 Jan;S0165-1781(18)32084-5.
28 Jovicich J, Marizzoni M, Sala-Llonch R, Bosch B, Bartrés-Faz D, Arnold J, et al.; PharmaCog Consortium. Brain morphometry reproducibility in multi-center 3T MRI studies: a comparison of cross-sectional and longitudinal segmentations. Neuroimage. 2013 Dec;83: 472-84.

29 Chi JG, Dooling EC, Gilles FH. Gyral development of the human brain. Ann Neurol. 1977 Jan;1(1):86-93.

30 White T, Su S, Schmidt M, Kao CY, Sapiro G. The development of gyrification in childhood and adolescence. Brain Cogn. 2010 Feb;72(1): 36-45.

31 Szymkowicz SM, Woods AJ, Dotson VM, Porges EC, Nissim NR, O'Shea A, et al. Associations between subclinical depressive symptoms and reduced brain volume in middleaged to older adults. Aging Ment Health. 2019 Jul;23(7):819-830.

32 Osler M, Sørensen L, Rozing M, Calvo OP, Nielsen M, Rostrup E. Subclinical depressive symptoms during late midlife and structural brain alterations: A longitudinal study of Danish men born in 1953. Hum Brain Mapp. 2018 Apr;39(4):1789-95.

33 O'Shea DM, Dotson VM, Woods AJ, Porges EC, Williamson JB, O'Shea A, et al. Depressive Symptom Dimensions and Their Association with Hippocampal and Entorhinal Cortex Volumes in Community Dwelling Older Adults. Front Aging Neurosci. 2018 Feb;10:40.

34 Spalletta G, Piras F, Caltagirone C, Fagioli S. Hippocampal multimodal structural changes and subclinical depression in healthy individuals. J Affect Disord. 2014 Jan;152-154:10512.

35 Goveas JS, Espeland MA, Hogan P, Dotson V, Tarima S, Coker LH, et al. Depressive symptoms, brain volumes and subclinical cerebrovascular disease in postmenopausal women: the Women's Health Initiative MRI Study. J Affect Disord. 2011 Jul;132(1-2):275-84.

36 Dotson VM, Davatzikos C, Kraut MA, Resnick SM. Depressive symptoms and brain volumes in older adults: a longitudinal magnetic resonance imaging study. J Psychiatry Neurosci. 2009 Sep;34(5):367-75.

37 Taki Y, Kinomura S, Awata S, Inoue K, Sato $\mathrm{K}$, Ito $\mathrm{H}$, et al. Male elderly subthreshold depression patients have smaller volume of medial part of prefrontal cortex and precentral gyrus compared with age-matched normal subjects: a voxel-based morphometry. J Affect Disord. 2005 Nov;88(3):313-20.

38 Webb CA, Weber M, Mundy EA, Killgore WD. Reduced gray matter volume in the anterior cingulate, orbitofrontal cortex and thalamus as a function of mild depressive symptoms: a voxel-based morphometric analysis. Psychol Med. 2014 Oct;44(13):2833-43. 
39 Hayakawa YK, Sasaki H, Takao H, Hayashi N, Kunimatsu A, Ohtomo K, et al. Depressive symptoms and neuroanatomical structures in community-dwelling women: A combined voxel-based morphometry and diffusion tensor imaging study with tract-based spatial statistics. Neuroimage Clin. 2014 Mar;4:481-7.

40 Hayakawa YK, Sasaki H, Takao H, Mori H, Hayashi N, Kunimatsu A, et al. Structural brain abnormalities in women with subclinical depression, as revealed by voxel-based morphometry and diffusion tensor imaging. I Affect Disord. 2013 Jan;144(3):263-8.

41 McLaren ME, Szymkowicz SM, O'Shea A, Woods AJ, Anton SD, Dotson VM. Dimensions of depressive symptoms and cingulate volumes in older adults. Transl Psychiatry. 2016 Apr;6(4):e788.

42 Szymkowicz SM, McLaren ME, Kirton JW, O'Shea A, Woods AJ, Manini TM, et al. Depressive symptom severity is associated with increased cortical thickness in older adults. Int J Geriatr Psychiatry. 2016 Apr;31(4):32533.

43 Carlson JM, Depetro E, Maxwell J, HarmonJones E, Hajcak G. Gender moderates the association between dorsal medial prefrontal cortex volume and depressive symptoms in a subclinical sample. Psychiatry Res. 2015 Aug; 233(2):285-8

44 McLaren ME, Szymkowicz SM, O'Shea A, Woods AJ, Anton SD, Dotson VM. Vertexwise examination of depressive symptom dimensions and brain volumes in older adults. Psychiatry Res Neuroimaging. 2017 Feb;260: $70-5$.

45 Besteher B, Gaser C, Langbein K, Dietzek M, Sauer H, Nenadić I. Effects of subclinical depression, anxiety and somatization on brain structure in healthy subjects. J Affect Disord. 2017 Jun;215:111-7.

46 Szymkowicz SM, Dotson VM, McLaren ME, De Wit L, O'Shea DM, Talty FT, et al. Precuneus abnormalities in middle-aged to older adults with depressive symptoms: an analysis of BDI-II symptom dimensions. Psychiatry Res Neuroimaging. 2017 Oct;268:9-14.

47 Potvin O, Catheline G, Bernard C, Meillon C, Bergua V, Allard M, et al. Gray matter characteristics associated with trait anxiety in older adults are moderated by depression. Int Psychogeriatr. 2015 Nov;27(11):1813-24.

48 Baur V, Hänggi J, Jäncke L. Volumetric associations between uncinate fasciculus, amygdala, and trait anxiety. BMC Neurosci. 2012 Jan;13(1):4.

49 Barrós-Loscertales A, Meseguer V, Sanjuán A, Belloch V, Parcet MA, Torrubia R, et al. Behavioral Inhibition System activity is associated with increased amygdala and hippocampal gray matter volume: A voxel-based morphometry study. Neuroimage. 2006 Nov; 33(3):1011-5.
50 Iidaka T, Matsumoto A, Ozaki N, Suzuki T, Iwata N, Yamamoto Y, et al. Volume of left amygdala subregion predicted temperamental trait of harm avoidance in female young subjects. A voxel-based morphometry study. Brain Res. 2006 Dec;1125(1):85-93.

$51 \mathrm{Hu}$ Y, Moore M, Bertels Z, Phan KL, Dolcos F, Dolcos S. Smaller amygdala volume and increased neuroticism predict anxiety symptoms in healthy subjects: A volumetric approach using manual tracing. Neuropsychologia. 2017 Nov;S0028-3932(17)30419-0.

52 Blackmon K, Barr WB, Carlson C, Devinsky O, DuBois J, Pogash D, et al. Structural evidence for involvement of a left amygdala-orbitofrontal network in subclinical anxiety. Psychiatry Res. 2011 Dec;194(3):296-303.

53 Spampinato MV, Wood JN, De Simone V, Grafman J. Neural correlates of anxiety in healthy volunteers: a voxel-based morphometry study. J Neuropsychiatry Clin Neurosci. 2009;21(2):199-205.

54 Pujol J, López A, Deus J, Cardoner N, Vallejo J, Capdevila A, et al. Anatomical variability of the anterior cingulate gyrus and basic dimensions of human personality. Neuroimage. 2002 Apr;15(4):847-55.

55 Donzuso G, Cerasa A, Gioia MC, Caracciolo $\mathrm{M}$, Quattrone A. The neuroanatomical correlates of anxiety in a healthy population: differences between the State-Trait Anxiety Inventory and the Hamilton Anxiety Rating Scale. Brain Behav. 2014 Jul;4(4):504-14.

56 Kühn S, Schubert F, Gallinat J. Structural correlates of trait anxiety: reduced thickness in medial orbitofrontal cortex accompanied by volume increase in nucleus accumbens. J Affect Disord. 2011 Nov;134(1-3):315-9.

57 Yamasue H, Abe O, Suga M, Yamada H, Inoue $\mathrm{H}$, Tochigi $\mathrm{M}$, et al. Gender-common and -specific neuroanatomical basis of human anxiety-related personality traits. Cereb Cortex. 2008 Jan; 18(1):46-52.

58 Cherbuin N, Windsor TD, Anstey KJ, Maller JJ, Meslin C, Sachdev PS. Hippocampal volume is positively associated with behavioural inhibition (BIS) in a large community-based sample of mid-life adults: the PATH through life study. Soc Cogn Affect Neurosci. 2008 Sep;3(3):262-9.

59 Wu H, Zhou R, Zhao L, Qiu J, Guo C. Neural bases underlying the association between balanced time perspective and trait anxiety. Behav Brain Res. 2019 Feb;359:206-14.

60 Fuentes P, Barrós-Loscertales A, Bustamante JC, Rosell P, Costumero V, Ávila C. Individual differences in the Behavioral Inhibition System are associated with orbitofrontal cortex and precuneus gray matter volume. Cogn Affect Behav Neurosci. 2012 Sep;12(3):491-8.

61 Miskovich TA, Pedersen WS, Belleau EL, Shollenbarger S, Lisdahl KM, Larson CL. Cortical Gyrification Patterns Associated with Trait Anxiety. PLoS One. 2016 Feb;11(2): e0149434.
62 Modi S, Thaploo D, Kumar P, Khushu S. Individual differences in trait anxiety are associated with gray matter alterations in hypothalamus: preliminary neuroanatomical evidence. Psychiatry Res Neuroimaging. 2019 Jan;283:45-54.

63 Besteher B, Squarcina L, Spalthoff R, Bellani M, Gaser C, Nenadić I, et al. Subclinical Agoraphobia Symptoms and Regional Brain Volumes in Non-clinical Subjects: Between Compensation and Resilience? Front Psychiatry. 2018 Nov;9:541.

$64 \mathrm{Hu} \mathrm{Y,} \mathrm{Dolcos} \mathrm{S.} \mathrm{Trait} \mathrm{anxiety} \mathrm{mediates} \mathrm{the}$ link between inferior frontal cortex volume and negative affective bias in healthy adults. Soc Cogn Affect Neurosci. 2017 May;12(5): $775-82$.

65 Wei D, Du X, Li W, Chen Q, Li H, Hao X, et al. Regional gray matter volume and anxietyrelated traits interact to predict somatic complaints in a non-clinical sample. Soc Cogn Affect Neurosci. 2015 Jan;10(1):122-8.

66 Antonenko D, Flöel A. Healthy aging by staying selectively connected: a mini-review. Gerontology. 2014;60(1):3-9.

67 Kaczkurkin AN, Raznahan A, Satterthwaite TD. Sex differences in the developing brain: insights from multimodal neuroimaging. Neuropsychopharmacology. 2019 Jan;44(1): 71-85.

68 Yagi S, Galea LA. Sex differences in hippocampal cognition and neurogenesis. Neuropsychopharmacology. 2019 Jan;44(1):20013.

$69 \mathrm{Hu} \mathrm{S}$, Ide JS, Chao HH, Castagna B, Fischer KA, Zhang S, et al. Structural and functional cerebral bases of diminished inhibitory control during healthy aging. Hum Brain Mapp. 2018 Dec;39(12):5085-96.

70 Amodio DM, Frith CD. Meeting of minds: the medial frontal cortex and social cognition. Nat Rev Neurosci. 2006 Apr;7(4):268-77.

71 Buckner RL, Andrews-Hanna JR, Schacter DL. The brain's default network: anatomy, function, and relevance to disease. Ann N Y Acad Sci. 2008 Mar;1124(1):1-38.

72 Decety J, Jackson PL, Sommerville JA, Chaminade T, Meltzoff AN. The neural bases of cooperation and competition: an fMRI investigation. Neuroimage. 2004 Oct;23(2):744-51.

73 Höflich A, Ganger S, Tik M, Hahn A, Kranz GS, Vanicek T, et al. Imaging the neuroplastic effects of ketamine with VBM and the necessity of placebo control. Neuroimage. 2017 Feb;147:198-203.

74 Kanai R, Rees $\mathrm{G}$. The structural basis of interindividual differences in human behaviour and cognition. Nat Rev Neurosci. $2011 \mathrm{Apr}$; 12(4):231-42.

75 Takeuchi H, Taki Y, Sassa Y, Hashizume H, Sekiguchi A, Fukushima A, et al. Regional gray matter density associated with emotional intelligence: evidence from voxel-based morphometry. Hum Brain Mapp. 2011 Sep;32(9): 1497-510. 
76 Besteher B, Squarcina L, Spalthoff R, Bellani M, Gaser C, Brambilla P, et al. Brain structural correlates of irritability: findings in a large healthy cohort. Hum Brain Mapp. 2017 Dec;38(12):6230-8.

$77 \mathrm{Hu}$ Y, Liu P, Guo Y, Feng T. The neural substrates of procrastination: A voxel-based morphometry study. Brain Cogn. 2018 Mar;121: 11-6.

78 Liu H, Wang Y, Liu W, Wei D, Yang J, Du X, et al. Neuroanatomical correlates of attitudes toward suicide in a large healthy sample: A voxel-based morphometric analysis. Neuropsychologia. 2016 Jan;80:185-93.

79 Hatano K, Terao T, Hoaki N, Kohno K, Araki Y, Mizokami Y, et al. Association between affective temperaments and regional gray matter volume in healthy subjects. J Affect Disord. 2014 Feb;155:169-73.

80 Botvinick MM, Cohen JD, Carter CS. Conflict monitoring and anterior cingulate cortex: an update. Trends Cogn Sci. 2004 Dec;8(12): 539-46.

81 Mansouri FA, Buckley MJ, Tanaka K. Mnemonic function of the dorsolateral prefrontal cortex in conflict-induced behavioral adjustment. Science. 2007 Nov;318(5852):987-90.

82 Hutton C, Draganski B, Ashburner J, Weiskopf N. A comparison between voxel-based cortical thickness and voxel-based morphometry in normal aging. Neuroimage. 2009 Nov; 48(2):371-80.

83 Freeman SH, Kandel R, Cruz L, Rozkalne A, Newell K, Frosch MP, et al. Preservation of neuronal number despite age-related cortical brain atrophy in elderly subjects without $\mathrm{Al}-$ zheimer disease. J Neuropathol Exp Neurol. 2008 Dec;67(12):1205-12.

84 Winkler AM, Kochunov P, Blangero J, Almasy L, Zilles K, Fox PT, et al. Cortical thickness or grey matter volume? The importance of selecting the phenotype for imaging genetics studies. Neuroimage. 2010 Nov;53(3):113546.

85 Alemán-Gómez Y, Janssen J, Schnack H, Balaban E, Pina-Camacho L, Alfaro-Almagro F, et al. The human cerebral cortex flattens during adolescence. J Neurosci. 2013 Sep;33(38): 15004-10.

86 Hogstrom LJ, Westlye LT, Walhovd KB, Fjell AM. The structure of the cerebral cortex across adult life: age-related patterns of surface area, thickness, and gyrification. Cereb Cortex. 2013 Nov;23(11):2521-30.

87 Klein D, Rotarska-Jagiela A, Genc E, Sritharan S, Mohr H, Roux F, et al. Adolescent brain maturation and cortical folding: evidence for reductions in gyrification. PLoS One. 2014 Jan;9(1):e84914.

88 Dauvermann MR, Mukherjee P, Moorhead WT, Stanfield AC, Fusar-Poli P, Lawrie SM, et al. Relationship between gyrification and functional connectivity of the prefrontal cortex in subjects at high genetic risk of schizophrenia. Curr Pharm Des. 2012;18(4):434-42.
89 Nixon NL, Liddle PF, Nixon E, Worwood G, Liotti M, Palaniyappan L. Biological vulnerability to depression: linked structural and functional brain network findings. Br J Psychiatry. 2014;204(4):283-9.

90 Schaer M, Ottet MC, Scariati E, Dukes D, Franchini M, Eliez S, et al. Decreased frontal gyrification correlates with altered connectivity in children with autism. Front Hum Neurosci. 2013 Nov;7:750.

91 Yotter RA, Nenadic I, Ziegler G, Thompson PM, Gaser C. Local cortical surface complexity maps from spherical harmonic reconstructions. Neuroimage. 2011 Jun;56(3): 961-73.

92 Sluming V, Barrick T, Howard M, Cezayirli E, Mayes A, Roberts N. Voxel-based morphometry reveals increased gray matter density in Broca's area in male symphony orchestra musicians. Neuroimage. 2002 Nov; 17(3):1613-22.

93 Watson D, Stanton K, Clark LA. Self-report indicators of negative valence constructs within the research domain criteria (RDoC): A critical review. J Affect Disord. 2017 Jul; 216:58-69.

94 Zhang K, Zhu Y, Zhu Y, Wu S, Liu H, Zhang W, et al. Molecular, Functional, and Structural Imaging of Major Depressive Disorder. Neurosci Bull. 2016 Jun;32(3):273-85.

95 Lai CH. Gray matter volume in major depressive disorder: a meta-analysis of voxelbased morphometry studies. Psychiatry Res. 2013 Jan;211(1):37-46.

96 Du MY, Wu QZ, Yue Q, Li J, Liao Y, Kuang $\mathrm{WH}$, et al. Voxelwise meta-analysis of gray matter reduction in major depressive disorder. Prog Neuropsychopharmacol Biol Psychiatry. 2012 Jan;36(1):11-6.

97 Bora E, Fornito A, Pantelis C, Yücel M. Gray matter abnormalities in Major Depressive Disorder: a meta-analysis of voxel based morphometry studies. J Affect Disord. 2012 Apr;138(1-2):9-18

98 Botvinick MM. Conflict monitoring and decision making: reconciling two perspectives on anterior cingulate function. Cogn Affect Behav Neurosci. 2007 Dec;7(4):356-66.

99 Decety J, Moriguchi Y. The empathic brain and its dysfunction in psychiatric populations: implications for intervention across different clinical conditions. Biopsychosoc Med. 2007 Nov;1(1):22.

100 Smoski MJ, Felder J, Bizzell J, Green SR, Ernst M, Lynch TR, et al. fMRI of alterations in reward selection, anticipation, and feedback in major depressive disorder. J Affect Disord. 2009 Nov;118(1-3):69-78.

101 Carter CS, Braver TS, Barch DM, Botvinick MM, Noll D, Cohen JD. Anterior cingulate cortex, error detection, and the online monitoring of performance. Science. 1998 May; 280(5364):747-9.

102 Malykhin NV, Coupland NJ. Hippocampal neuroplasticity in major depressive disorder. Neuroscience. 2015 Nov;309:200-13.
103 Stratmann M, Konrad C, Kugel H, Krug A, Schöning S, Ohrmann $\mathrm{P}$, et al. Insular and hippocampal gray matter volume reductions in patients with major depressive disorder. PLoS One. 2014 Jul;9(7):e102692.

104 Price JL, Drevets WC. Neurocircuitry of mood disorders. Neuropsychopharmacology. 2010 Jan;35(1):192-216.

105 Stephani C, Fernandez-Baca Vaca G, Maciunas R, Koubeissi M, Lüders HO. Functional neuroanatomy of the insular lobe. Brain Struct Funct. 2011 Jun;216(2):137-49.

106 Cauda F, D’Agata F, Sacco K, Duca S, Geminiani G, Vercelli A. Functional connectivity of the insula in the resting brain. Neuroimage. 2011 Mar;55(1):8-23.

107 Turner AD, Furey ML, Drevets WC, Zarate C Jr, Nugent AC. Association between subcortical volumes and verbal memory in unmedicated depressed patients and healthy controls. Neuropsychologia. 2012 Jul;50(9): 2348-55.

108 Kaymak SU, Demir B, Sentürk S, Tatar I, Aldur MM, Uluğ B. Hippocampus, glucocorticoids and neurocognitive functions in patients with first-episode major depressive disorders. Eur Arch Psychiatry Clin Neurosci. 2010 Apr;260(3):217-23.

109 Warner-Schmidt JL, Duman RS. Hippocampal neurogenesis: opposing effects of stress and antidepressant treatment. Hippocampus. 2006;16(3):239-49.

110 MacQueen GM, Campbell S, McEwen BS, Macdonald K, Amano S, Joffe RT, et al Course of illness, hippocampal function, and hippocampal volume in major depression. Proc Natl Acad Sci USA. 2003 Feb; 100(3):1387-92.

111 Campbell KL, Grigg O, Saverino C, Churchill $\mathrm{N}$, Grady CL. Age differences in the intrinsic functional connectivity of default network subsystems. Front Aging Neurosci. 2013 Nov; $5: 73$.

112 Fox MD, Snyder AZ, Vincent JL, Corbetta M, Van Essen DC, Raichle ME. The human brain is intrinsically organized into dynamic, anticorrelated functional networks. Proc Natl Acad Sci USA. 2005 Jul;102(27):96738.

113 Posner J, Hellerstein DJ, Gat I, Mechling A, Klahr K, Wang Z, et al. Antidepressants normalize the default mode network in patients with dysthymia. JAMA Psychiatry. 2013 Apr;70(4):373-82.

114 Lois G, Wessa M. Differential association of default mode network connectivity and rumination in healthy individuals and remitted MDD patients. Soc Cogn Affect Neurosci. 2016 Nov;11(11):1792-801.

115 Nejad AB, Fossati P, Lemogne C. Self-referential processing, rumination, and cortical midline structures in major depression. Front Hum Neurosci. 2013 Oct;7:666. 
116 Qiu L, Lui S, Kuang W, Huang X, Li J, Li J, et al. Regional increases of cortical thickness in untreated, first-episode major depressive disorder. Transl Psychiatry. 2014 Apr;4(4): e378.

117 Bishop SJ. Neurocognitive mechanisms of anxiety: an integrative account. Trends Cogn Sci. 2007 Jul;11(7):307-16.

118 Adolphs R, Tranel D, Damasio H, Damasio AR. Fear and the human amygdala. J Neurosci. 1995 Sep;15(9):5879-91.

119 Charney DS, Deutch A. A functional neuroanatomy of anxiety and fear: implications for the pathophysiology and treatment of anxiety disorders. Crit Rev Neurobiol. 1996; 10(3-4):419-46.

120 LeDoux JE. Emotion: clues from the brain. Annu Rev Psychol. 1995;46(1):209-35.

121 LaBar KS, Cabeza R. Cognitive neuroscience of emotional memory. Nat Rev Neurosci. 2006 Jan;7(1):54-64.

122 Dolcos F, LaBar KS, Cabeza R. Interaction between the amygdala and the medial temporal lobe memory system predicts better memory for emotional events. Neuron. 2004 Jun;42(5):855-63.
123 Halgren E, Smith ME. Cognitive evoked potentials as modulatory processes in human memory formation and retrieval. Hum Neurobiol. 1987;6(2):129-39.

124 Kilpatrick L, Cahill L. Amygdala modulation of parahippocampal and frontal regions during emotionally influenced memory storage. Neuroimage. 2003 Dec;20(4):20919.

125 Ochsner KN, Silvers JA, Buhle JT. Functional imaging studies of emotion regulation: a synthetic review and evolving model of the cognitive control of emotion. Ann N Y Acad Sci. 2012 Mar;1251(1):E1-24.

126 Morris JS, Dolan RJ. Dissociable amygdala and orbitofrontal responses during reversal fear conditioning. Neuroimage. 2004 May; 22(1):372-80.

127 Gottfried JA, Dolan RJ. Human orbitofrontal cortex mediates extinction learning while accessing conditioned representations of value. Nat Neurosci. 2004 Oct;7(10):114452.
128 Kim MJ, Loucks RA, Palmer AL, Brown AC Solomon KM, Marchante AN, et al. The structural and functional connectivity of the amygdala: from normal emotion to pathological anxiety. Behav Brain Res. 2011 Oct; 223(2):403-10.

129 Sehlmeyer C, Dannlowski U, Schöning S, Kugel H, Pyka M, Pfleiderer B, et al. Neural correlates of trait anxiety in fear extinction. Psychol Med. 2011 Apr;41(4):789-98.

130 Modi S, Kumar M, Kumar P, Khushu S. Aberrant functional connectivity of resting state networks associated with trait anxiety. Psychiatry Res. 2015 Oct;234(1):25-34.

131 Imperatori C, Farina B, Adenzato M, Valenti EM, Murgia C, Marca GD, et al. Default mode network alterations in individuals with high-trait-anxiety: an EEG functional connectivity study. J Affect Disord. 2019 Mar;246:611-8.

132 Xu J, Van Dam NT, Feng C, Luo Y, Ai H, Gu $\mathrm{R}$, et al. Anxious brain networks: A coordinate-based activation likelihood estimation meta-analysis of resting-state functional connectivity studies in anxiety. Neurosci Biobehav Rev. 2019 Jan;96:21-30. 